\title{
OVERVIEW OF INTERPRETIVE STRUCTURAL MODELING
}

\author{
Ashok kumar ( M.Tech) \\ Mechanical Department \\ J.C BOSE YMCAUST \\ Faridabad Haryana India
}

\author{
Dr. Vikram Singh (Professor) \\ Mechanical Department \\ J.C BOSE YMCAUST \\ Faridabad Haryana India
}

\begin{abstract}
Interpretive Structural Modelling is a wellproven method, in this method deals with complex relationship among the identifying items, which are define the issue. ISM generates a visual model of identifying items, which is directly and indirectly related factors, and explains strong and weak driving power and dependences power of identifying items. In this methodology, started with an identification of factors, which are related to issues. After that a logically applicable subordinate connection is chosen. Having chosen the relevant connection, an auxiliary selfinteraction matrix (SSIM) is creating dependent on pair wise comparison of factors. After this, SSIM is changing over into a reachability matrix (RM) and its transitivity is checked. When transitivity inserting is finished, a graphical model is obtained. At that point, the dividing of the components and an extraction of the basic model called ISM is determined
\end{abstract}

\section{INTRODUCTION}

J. Warfield (1973) fist time purposed Interpretive Structural Modelling (ISM). Interpretive Structural Modelling is a computer assisted learning process. It manages complex relation between the numerous factors associated with a complex situation. ISM is regularly used to give essential appreciation of complex conditions, as well as collect a technique for solving an issue. Various elevated affiliations or researchers have used it worldwide.

This approach starts with identifications of barriers which are affecting the problem. Than pair wise interrelation ship are established between the identifying barriers. Further, develop a structural self interaction matrix (SSIM) on the basis of pair wise interrelation ship established between the barriers. Than develop an initial reachability matrix with the help specific rule. Further develop a final reachability matrix with the help of transitivity rule. After that, iteration matrix is developed by segregation of reachability set, antecedent set and interaction set of both. Iteration is done afterwards and level is assigned and the corresponding values are omitted. In next iteration until all the value are omitted. On the base iteration performed factors are arranged from the most critical in last level and least critical in the first level. Conical matrix is developed with the help of FRM along with the iteration level to find drive power and dependence power. A digraph is made in ascending order of level which means the most critical barrier will be represented at last in the digraph, and the least critical at the top of the digraph interconnected by nodes. Nodes are replaced by a statement which leads to creation of Model from the digraph. Model helps in analyzing the most and least critical factors in real time. In case of any conceptual inconsistency, the above steps are repeated. Else, the process is continued.

MICMAC Analysis based on conical matrix is analyzing wherein dependency power and driving powers are plotted on a graph. Graph is divides into Autonomous, Dependent, Linkages, and Independent factors. These values in the graphs are deriving from conical matrix. Necessary modification and theoretical discrepancies are integrated. In case of any conceptual inconsistency, the above steps are repeating; else, the process is continued.

Concept Star Professional ISM Software and Training Package gives the fundamental programming and all data required to learn and utilize the ISM decision-making method effectively. 
International Journal of Engineering Applied Sciences and Technology, 2019

Vol. 4, Issue 5, ISSN No. 2455-2143, Pages 536-540

Published Online September 2019 in IJEAST (http://www.ijeast.com)

Flow chart of ISM

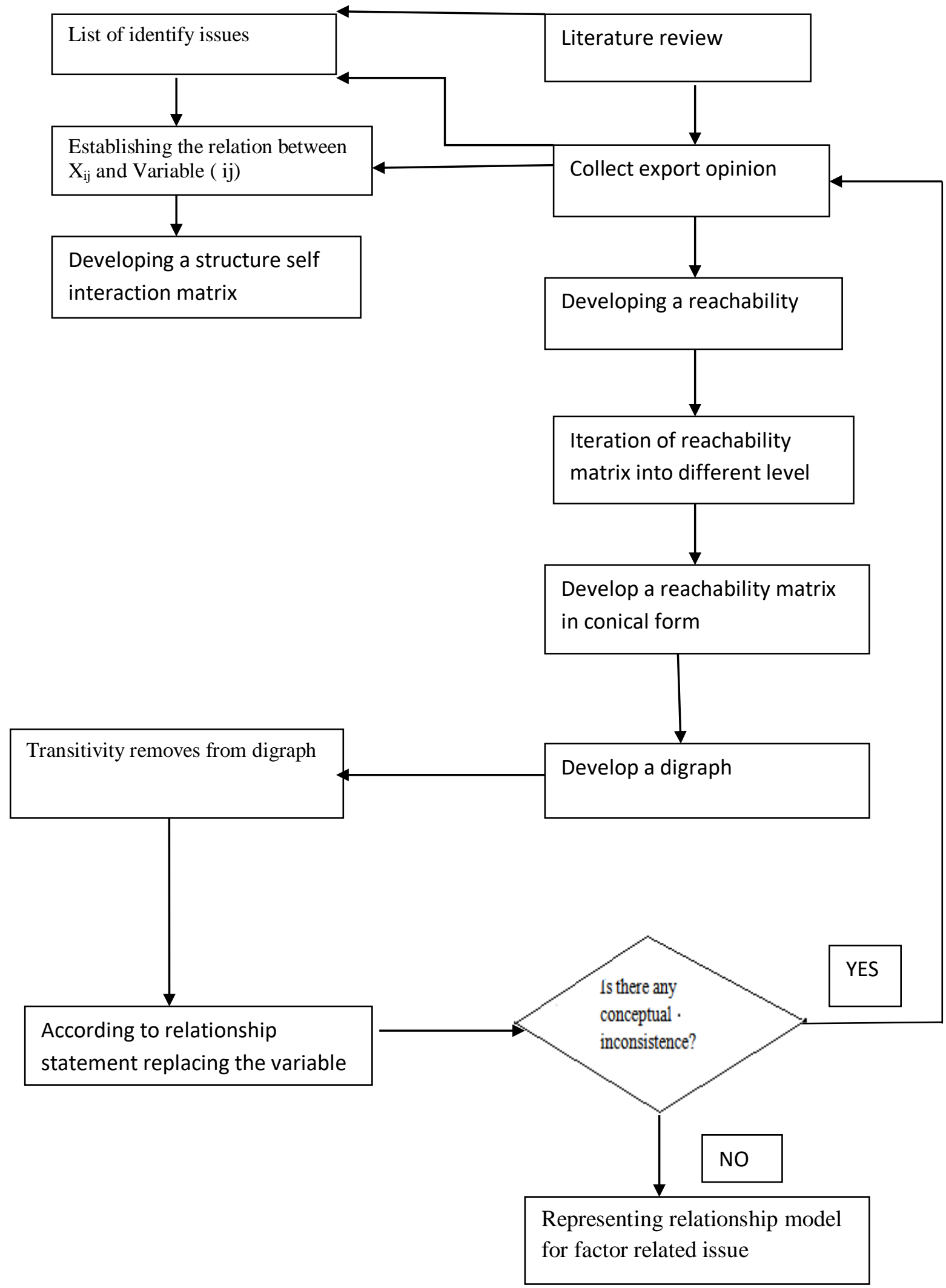




\section{International Journal of Engineering Applied Sciences and Technology, 2019 \\ Vol. 4, Issue 5, ISSN No. 2455-2143, Pages 536-540 \\ Published Online September 2019 in IJEAST (http://www.ijeast.com)}

\section{STEPS INVOLVED IN ISM TECHNIQUE}

\section{STEP 1}

Barriers are identifying, which are relate to problem and represented in tabular form.

\section{STEP 2}

Structural Self-interactive matrix (SSIM) is being made by identifying relations between factors, which is an outcome of discussion with the experts and is represented in Table with the help of symbols as per the below list:

- $(i, j)$ - i represents column of table and $\mathrm{j}$ represents rows.

- $\quad v-$ Forward relation ( $i$ is related to $j$ )

- $A$ - reverse relation ( $j$ is related to $i$ )

- $\quad \mathrm{o}-$ no relation between $\mathrm{i}$ and $\mathrm{j}$

- $\mathrm{x}$ - Represents reversible relation between $\mathrm{i}$ and $\mathrm{j}$.

\section{STEP 3}

In Structural Self- Interaction matrix (SSIM), if the value of $\mathrm{i}$ and $\mathrm{j}$ is $\mathrm{V}$, the corresponding value in Initial Reachability Matrix (IRM) becomes 1 and the reverse of it i.e. the value of $\mathrm{j}$ and $\mathrm{i}$ becomes 0 .

If in SSIM, value of $i$ and $\mathrm{j}$ is $\mathrm{A}$, corresponding value in IRM becomes 0 and the value of $j$ and $i$ becomes 1 .

For value of $i$ and $\mathrm{j}$ is $\mathrm{X}$ in SSIM, corresponding value in IRM becomes 1 and the value of $\mathrm{j}$ and $\mathrm{i}$ becomes 1 .

If in SSIM, value of $i$ and $j$ is $O$, corresponding value in IRM becomes 0 and the value of $j$ and $i$ becomes 0 .

\section{STEP 4}

Final Reachability Matrix (FRM), representeing in Table, is constructeing by finding transitivity in the matrix, which is an indirect relation between factors. If transitivity is found in the matrix, the final transitivity matrix value is put as $1 *$.

\section{STEP 5}

Further, iteration matrix is developing by segregation of reachability set, antecedent set and interaction set of both, as shown in Table. In this, the value is obtaining from FRM. 1 in the corresponding row is taken in reachability set. 1 in the corresponding column is taken in accident set. Value common in both reachability set and antecedent set is taken in Intersection set. Iteration is done afterwards, level is assigned, and the corresponding values are omitted in next iteration until all the values are omitted.

\section{STEP 6}

On the base iteration performed barriers are arranged from the most critical i.e. last level to least critical i.e. the first level and is represented in figure.

\section{STEP 7}

Conical matrix is developed with the help of FRM along with the iteration level to find drive power and dependence power as shows in Table.

\section{STEP 8}

A digraph is modes in ascending order of level, which means the most critical barrier, will be represented at last in the digraph, and the least critical at the top of the digraph interconnected by nodes.

\section{STEP 9}

Nodes are replacing by statements, which leads to creation of Model from the digraph. Model helps in analyzing the most and least critical factors in real time.

\section{STEP 10}

In case of any conceptual inconsistency, the above steps are repeated. Else, the process is continued.

\section{STEP 11}

MICMAC (Matrice d'Impacts croises-multiplication application) Analysis based on conical matrix is analysed wherein dependency power and driving power are plotted on a graph. Graph is dividing into Autonomous, Dependent, Linkages, and Independent factors. These values in the graph are deriving from conical matrix.

In this analysis, analysis is done between the driver power and dependence power of the element. MICMAC analysis graphically shows the driving and dependency power of the elements, which helps in analyzing the strong and weak driving power. In this analysis, a graph is plotted between driver power and dependence power, $\mathrm{X}$-axis represents the dependency power, and y-axis represents the driver power. The graph is plotted on the basis of conical matrix. The drivers are further categorized in four categories detailed as below: (i) Autonomous driver (ii) Dependent driver (iii) Linkage driver (iv) Independent driver. Autonomous driver shows weak drive power and weak dependence power. Dependent driver explain strong dependency power and weak driver power. Linkage explains both strong driving and dependence power. It is unstable. Any change in this may give positive or negative effect on manpower planning. Independent drive explains strong driver power and weak dependence power. 


\section{International Journal of Engineering Applied Sciences and Technology, 2019 \\ Vol. 4, Issue 5, ISSN No. 2455-2143, Pages 536-540 \\ Published Online September 2019 in IJEAST (http://www.ijeast.com)}

\section{STEP 12}

Necessary modification and theoretical discrepancies are integrated and is shows in figure.

\section{ADVANTAGES OF ISM APPROACH}

- The procedure is more efficient; contingent upon the unique situation, the utilization of transitive derivation may diminish the quantity of the required relation inquiries by from $70-80$ percent.

- No information of the hidden procedure is expected of the members; they just should have enough comprehension of the item framework to have the option to react to the arrangement of related questions produced by the computer.

- The procedure is precise; the computer program is modified to consider all possible pair wise relations of framework components, either legitimately from the reactions of the members or by transitive induction.

- It guides and records the effects of gathering consultations on complex issues in an effective and precise way.

- It produces an organized model or graphical representation of the issue circumstance that can be discus more effectively to other people.

- It improves the nature of interdisciplinary and relational correspondence inside the setting of the issue circumstance by concentrating of the members on one explicit inquiry at any given moment.

- It fills in as a learning apparatus by compelling members to build up a more profound comprehension of the importance and criticalness of a predefined component rundown and connection.

- It licenses activity or strategy examination by helping members in distinguishing specific zones for arrangement activity which offer points of interest or influence in seeking after indicated goals.

- It supports issue investigation by enabling members to investigate the ampleness of a proposed rundown of frameworks components or issue proclamations for lighting up a predetermined circumstance.

\section{LIMITATIONS OF ISM APPROACH}

In this method, limiting factors are considered, as increasing the number of factors increases the complexity of the ISM model. Therefore we can consider the limiting factors in the development of the ISM model. Other cars that are less affected by the problem do not consider it. It is helpful to seek the help of expert to analyze the least influential factor.

\section{APPLICATIONS OF ISM APPROACH:}

This model is using at a high level. With the help of this method, we get a visual model of a complex problem, so that we can easily analyze a complex problem. We use this model in many fields. Such as strategic planning, product design, complex technical problems, career planning, design, engineering problems, financial decision making, human resources, competitive analysis and electronic commerce etc. Literature has used this model in different fields. Such as:

Yuhan Wang et.al, Wenbing Wu et. al; Shuxiang Wang et.al (2018) have implemented this method to identifying the factors and in analyzing the mutual interaction between these factors of agricultural products logistics.

Jain, P et.al., Sharma, An et.al., and Ahuja, L et.al. (2016, September) have implemented this technique to recognizing the variables and in analyzing the mutual interaction between these components of agile development.

Kumar, $\mathrm{N}$ et.al, Kumar, $\mathrm{S}$ et.al., Haleem, A.et.al, and Gahlot, P.et.al (2013) have executed this strategy to distinguishing the variables and in analyzing the mutual interaction between these factors of lean manufacturing system.

Ashok et.al (2019) have implemented this method to identifying the factors and in analyzing the mutual interaction between these factors of man power planning in small scale industry.

Bag, S et.al., \& Anand, N et.al (2014) have implemented this method to identifying the factors and in analyzing the mutual interaction between these factors of green supply chain management.

Ranjan Debata, B et.al., Sree, K., Patnaik, B et.al. and Sankar Mahapatra, S.et.al (2013) have executed this strategy to identifying the factors and in analyzing the mutual interaction between these factors of medical tourism.

Poduval, P. S.et.al \& Pramod, V. R.et.al (2015) have implemented this method to identifying the factors and in analyzing the mutual interaction between these factors of Total Productive Maintenance.

Azhar, S. Bet.al, and Talib, P.et.al (2015) have actualized this strategy to recognizing the variables and in investigating the common association between these components of Green management \& environmental sustainability. 


\section{International Journal of Engineering Applied Sciences and Technology, 2019 \\ Vol. 4, Issue 5, ISSN No. 2455-2143, Pages 536-540 \\ Published Online September 2019 in IJEAST (http://www.ijeast.com)}

Talib, F.et.al Rahman, Z.et.al and Qureshi, M. N.et.al (2011) have actualized this technique to identifying the factors of Total Quality Management in Service Sector.

Song, L., Li, Q.et.al, List, G.et.al, Deng, Y.et.al, \& Lu, P.et.al (2017) have implemented this method to identifying the factors and in analyzing the mutual interaction between these factors of urban rail transit system.

Haleem, A., Sushil, Qadri, M. An., and Kumar, S. (2012) have executed this strategy to identifying the variables and in dissecting the shared collaboration between these elements of world-class manufacturing.

Kumar Mittal, V.et.al \& Singh Sangwan, K.et.al (2014) have implemented this method to identifying the factors and in analyzing the mutual interaction between these factors of

Kumar Mittal, V.et.al and Singh Sangwan, K.et.al (2014) have actualized this technique to identifying the variables and in investigating the shared connection between these components of environmentally conscious manufacturing.

\section{CONCLUSION}

Interpretive Structural Modelling (ISM) provides a systematic order, for a complex problem gives a directional framework and decision. ISM provides a realistic picture of their situation and the factors involved. This method help to identifying the factors related to problem and in analyzing the mutual interaction between these factors. After the identification the factors have developed a strategy for dealing the problem. This method helps to rank order of the factors and direction to solve complex problems from a systems point of view. This method provides a model of the problem according to the rank of factors such that easy to analysis the problem. This method gives the relation between the factors driving power and dependency power. This method is very useful for complex problem.

\section{REFERENCES}

1. Wang, Y., Wu, W., \& Wang, S. (2018). Research on the development of agricultural products logistics in China based on ISM model. International Journal of Internet Manufacturing and Services, 5(1), (pp22-37).

2. Jain, P., Sharma, A., \& Ahuja, L. (2016, September). ISM based identification of quality attributes for agile development. In 2016 5th International Conference on Reliability, Infocom Technologies and Optimization (Trends and Future Directions)(ICRITO) (pp. 615-619). IEEE.

3. Kumar, N., Kumar, S., Haleem, A., \& Gahlot, P. (2013). Implementing lean manufacturing system:
ISM approach. Journal of Industrial Engineering and Management (JIEM), 6(4),(pp 996-1012).

4. Bag, S., \& Anand, N. (2014). Modeling green supply chain management framework using ISM and MICMAC analysis. African Journal of Business Management, 8(22),(pp 1053-1065).

5. Ranjan Debata, B., Sree, K., Patnaik, B., \& Sankar Mahapatra, S. (2013). Evaluating medical tourism enablers with interpretive structural modeling. Benchmarking: An International Journal, 20(6), (pp716-743).

6. Poduval, P. S., \& Pramod, V. R. (2015). Interpretive Structural Modeling (ISM) and its application in analyzing factors inhibiting implementation of Total Productive Maintenance (TPM). International Journal of Quality \& Reliability Management, 32(3), (pp308-331).

7. Azhar, S. B., \& Talib, P. (2015). Green management indicators \& environmental sustainability: an ISM based approach. The Business \& Management Review, 7(1),pp- 377.

8. Talib, F., Rahman, Z. and Qureshi, MN (2011)‘An interpretive structural modelling approach for modelling the practices of total quality management in service sector', Int. J. Modelling in Operations Management, 1(3), (pp223-250).

9. Song, L., Li, Q., List, G., Deng, Y., \& Lu, P. (2017). Using an AHP-ISM based method to study the vulnerability factors of urban rail transit system. Sustainability, 9(6),pp 1065.

10. Haleem, A., Sushil, Qadri, M. A., \& Kumar, S. (2012). Analysis of critical success factors of world-class manufacturing practices: an application of interpretative structural modelling and interpretative ranking process. Production Planning \& Control, 23(10-11), (pp722-734).

11. Kumar Mittal, V., \& Singh Sangwan, K. (2014). Modeling drivers for successful adoption of environmentally conscious manufacturing. Journal of Modelling in Management, 9(2),(pp 127-140). 